\title{
EDUCAÇÃO E PRODUÇÃO DE SUBJETIVIDADE: O RESSENTIMENTO COMO MÁQUINA DE PRODUZIR CORPOS
}

\author{
EDUCATION AND PRODUCTION OF SUBJECTIVITY: RESIDENCE AS A MACHINE FOR PRODUCING BODIES
}

EDUCACIÓN Y PRODUCCIÓN DE SUBJETIVIDAD: EL RENDIMIENTO COMO MÁQUINA DE PRODUCIR CUERPOS

RANIERE, Édio

RODRIGUES, Carla Gonçalves²

\begin{abstract}
RESUMO
O presente ensaio busca problematizar a produção de subjetividade em corpos docentes e discentes quando atravessados pelo ressentimento. Pautado pelo Método de Dramatização (DELEUZE, 1976; 2006) intenta colocar a questão o que quer. Para tal apresenta um personagem conceitual, 'o professor', e um personagem estético, 'o aluno'. A crítica realizada ao ressentimento abre, ao longo do texto, condições de possibilidade para que uma ética do eterno retorno (NIETZSCHE, 1995; 2012) se apresente como paradoxo à educação. Queres isso mais uma vez? Como queres? Com quais condições de possibilidades queres? O trabalho utiliza a ficção (COSTA, 2014) como disparador de uma política de escrita, tencionando a educação como prática de invenção de si.
\end{abstract}

Palavras-chave: Educação. Produção de Subjetividade. Ressentimento. Eterno Retorno.

\section{ABSTRACT}

The present essay seeks to problematize the production of subjectivity in teachers and students when they are overcome by resentment. Guided by the Method of Dramatization (Deleuze, 1976; 2006) seeks to put the question: what it wants. For this he presents a conceptual character, 'the teacher', and an aesthetic character, 'the student'. The criticism of resentment opens, throughout the text, conditions of possibility for an ethics of eternal return (Nietzsche, 1995; 2012) to present itself as a paradox to education. You want this one more time? As you wish? With what conditions do you want? The work uses fiction (Costa, 2014) as a trigger for a writing policy, intending education as a practice of self-invention

Keywords: Education. Subjectivity production. Resentment. Eternal return.

\section{RESUMEN}

El presente ensayo busca problematizar la producción de subjetividad en cuerpos docentes y discentes cuando atravesados por el resentimiento. En el caso de las mujeres, la mayoría de las veces, Para ello presenta un personaje conceptual, 'el profesor', y un personaje estético, 'el alumno'. La crítica realizada al resentimiento abre, a lo largo del texto, condiciones de posibilidad para que una ética del eterno retorno (Nietzsche, 1995; 2012) se presente como paradoja a la educación. ¿Quieres eso una vez más? ¿Cómo quieres? ¿Con qué condiciones de posibilidades quieres? El trabajo utiliza la ficción (Costa, 2014) como disparador de una política de escritura, pretendiendo la educación como práctica de invención de sí

Palabras clave: Educación. Producción de Subjetividad. Resentimiento. Eterno Retorno.

\footnotetext{
1 Universidade Federal de Pelotas - UFPel - Pelotas - Rio Grande do Sul - Brasil

2 Universidade Federal de Pelotas - UFPel - Pelotas - Rio Grande do Sul - Brasil
} 


\title{
SOBRE O ETERNO RETORNO DO RESSENTIMENTO E/OU PROFESSOR: QUERES ISSO MAIS UMA VEZ?
}

Mais uma quinta-feira. Quanto tempo tenho antes do inferno? - consultando o relógio na tela do notebook - Putz! Acho que vou atrasar-me novamente. Não aguento mais isso! não aguento mais! Que turma impossível! Não vejo a hora disto acabar, e ainda faltam dez aulas. Essa maldita greve atrasou tudo! Começamos apenas no final de março. Agora sou eu, como sempre, que pago o pato. Mais dez aulas. Que inferno! Se ao menos tivesse coragem de lecionar como o Silva, trabalharia com alguma bobagem, literatura, talvez (...). Será que deixaria as coisas mais leves? Quem sabe, hein!?! Perpassando o olhar pela estante da pequena biblioteca que mantinha em casa, o professor encontra um exemplar de 'Memórias do Subsolo', presente ganho no amigo secreto do ano passado:

\begin{abstract}
Sou um homem doente... Sou mau. Não tenho atrativos. Acho que sofro do fígado. Aliás, não entendo bulhufas da minha doença e não sei com certeza o que é que me dói. Não me trato, nunca me tratei, embora respeite os médicos e a medicina. Além de tudo, sou supersticioso ao extremo; bem, o bastante para respeitar a medicina. (Tenho instrução suficiente para não ser supersticioso, mas sou.) Não, senhores, se não quero me tratar é de raiva. Isso os senhores provavelmente não compreendem. Que assim seja, mas eu compreendo. Certamente, não poderia explicar a quem exatamente eu atinjo, nesse caso, com a minha raiva; sei perfeitamente que, não me tratando, não posso prejudicar os médicos; sei perfeitamente bem que, com isso, prejudico somente a mim e a mais ninguém. Mesmo assim, se não me trato, é de raiva. Se o fígado dói, que doa ainda mais. (DOSTOIÉVSKI, 2000, p. 15).
\end{abstract}

Sou um homem doente - risos em silêncio - Acho que me identifico um pouco com esse protagonista. Deveria me tratar? - devaneando por alguns segundos sobre a doença - Não! Não posso conceber. $O$ que esses alunos precisam é de um pulso firme, alguém que thes eduque corretamente. Não se pode ensinar de verdade com essas falcatruas modernas. Literatura! pigarreando - Me poupem! Não tenho tempo para isso. Além do que, tudo se transformaria em interpretação, avaliação, debate. Uma pedagogia que não tem certeza das verdades que professa é uma ciência frouxa, sem razão de ser. Desculpem-me, mas isso não é transmissão de conhecimento e sim uma conversa infinita. Ademais, Dostoiévski não deixaria as coisas mais leves e eu ainda teria que encontrar tempo para ler um romance para o qual nunca tive paciência. Talvez nas férias. Isso, nas férias, quando não tiver nada melhor para fazer. Se ao menos compreendessem que tudo que faço é para o bem deles. O que eu quero é apenas o melhor para meus alunos. Quero que eles aprendam, só isso. Ficam chateados comigo, me chamam de autoritário, mas como poderia ensiná-los se não mostrasse a diferença entre os bons e os maus alunos. Sei que não é prazeroso para ninguém ocupar a posição do ignorante. Mas, sem os imbecis, como notaríamos os inteligentes? Minha intenção é justamente ajudar esses burrinhos a evoluírem. E todos sabemos que, pedagogicamente, existe apenas uma maneira de fazer isso: o aluno precisa compreender o ponto onde ele se encontra na escada do conhecimento. Uma vez percebendo que está no segundo ou terceiro degrau, terá, aí sim, condições de programar seu percurso rumo ao ápice do conhecimento. O professor estará, então, à disposição dele como o grande especialista, um pai amável que se dedica a ensiná-lo, passo a passo, 
como conhecer, o que conhecer, para que conhecer. Todos têm as mesmas condições; todos são iguais em capacidade; ninguém é melhor que ninguém. Mas não podemos negar que alguns são bons enquanto outros são maus alunos. Foi assim que me ensinaram a ser professor e será dessa forma, gostem ou não, que seguirei ensinando.

Como dizia minha professora de psicanálise: vão se castrar. De qualquer forma, nada posso fazer além de seguir com o planejamento das aulas - conferindo mais uma vez o plano de ensino na tela do computador - Prova! Hoje tem prova. - vidrado na tela, deixando cair um pouco de saliva pelo canto esquerdo da boca - Finalmente. Agora eles vão compreender. Farei uma prova dificílima. Poucos conseguirão atingir a média. Pedi mil vezes para que não chegassem atrasados. Agora eles vão compreender! 'Professor, acho que caiu uma questão na prova que não vimos em aula'! Qual? 'Essa aqui!' Ah! Sim, falamos muito sobre isso, Maurício, foi no dia 20 de maio. Você chegou atrasado, lembra? 'Não!' Pois eu nunca esqueço. Guardo na memória cada dia, cada hora, cada gesto de vocês. Sou uma máquina mnemônica. Querem conferir no diário? Aqui está. Deus! Que sentimento maravilhoso! Gostaria de me sentir assim todos os dias. Ou então - rindo sozinho - Ah! Sim, foi no dia 08 de abril. Bruna, você lembra que passou a aula inteirinha, brincando no Facebook? Sim! Finalmente eles vão entender. Terei meu grande dia. Serei admirado, elogiado, aplaudido. Puxa, mas falando em Facebook, desde ontem à noite que não atualizo minha timeline. Vou dar uma espiada e depois monto a prova. É rapidinho.

\footnotetext{
Tal como nos apareceu, o ressentimento não se separa de um horrível convite, de uma tentação, de uma vontade de espalhar um contágio. Esconde seu ódio sob os auspícios de um amor tentador: é para teu bem que te acuso; eu te amo, para que te juntes a mim, até que te juntes a mim, até que tu mesmo te tornes um ser doloroso, doente, reativo, um ser bom... (DELEUZE, 1976, p. 60).
}

Esse Gilberto sempre a postar essas filosofadas que não servem pra nada. Ao invés de ficar divagando sobre essa ou aquela bobagem, deveria se concentrar nas aulas como eu faço. Se ele fosse mais rigoroso com os alunos, não me incomodariam tanto. Como fica sempre dando segunda, terceira chance para aluno relapso, acabam confundindo exigência com autoritarismo. Mas, o que é isso? O desgramado me marcou numa postagem. Não! Mas o que é isso? Somente eu, ninguém mais. Ele marcou apenas a mim. O que esse cretino está querendo dizer com isso? Ah! Mas vou ler agora mesmo:

A ética do nobre é uma ética da ação, da atividade, do querer. Não necessariamente de fazer tudo o que se quer, mas de querer tudo que se faz. Já a moral do ressentido é uma reação no sentido dialético. Moral agenciada pelo julgamento. Ou seja, o sujeito que vive sobre essa moralidade, para existir, para experimentar a vida, necessita sempre encontrar alguém para acusar. Encontrar o pecador, encontrar o malvado: eis a primeira tarefa imposta pela moral do ressentido. Esta moral do ressentimento, também chamada por Nietzsche (2009) de moral do escravo - em alusão ao povo Judeu em fuga do Egito - ou moral do rebanho, possui uma fórmula: ele é mau, logo eu sou bom. Trazendo para a prática do magistério, podemos pensar que se a ética do nobre afirma a existência em 
sua tragicidade, um professor investido por essa ética encontraria na docência uma vida como obra de arte, um território para invenção de si e de mundos, uma permanente artistagem. Já o professor capturado pela moral do escravo, dificilmente conseguiria fazer de seu magistério algo que não fosse uma ação de vingança.

Pois, lembremos, a moral do ressentido só funciona dialeticamente. Sem um outro para julgar, toda maquinaria entraria em colapso. Seria preciso, portanto, antes de mais nada, criar condições de possibilidade para que se possa acusar, julgar. A docência passa a ser um jogo acusatório, espécie de tribunal moral do conhecimento. Uma vez aprovados os métodos acusatórios, torna-se possível selecionar os maus alunos e, finalmente, o professor ressentido tem a oportunidade de utilizar a fórmula: ele é mau, logo eu sou bom. A partir dela, constrói as paisagens que sustentam sua frágil existência: ele é ignorante, logo eu sou o especialista nesta disciplina. Ele é relapso, logo sou exigente.

Dessa forma, ao avaliar o aluno com uma nota baixa ou até mesmo reprová-lo, este esse professor, via dialética do ressentido, sente-se um bom professor. Como música, ouve a fórmula da moral do escravo cantar em seu ouvido: o aluno foi relaxado, logo você é implacável. O aluno foi incompetente, logo você é o máximo. O aluno avaliou errado o conceito, logo você avaliou corretamente.

O prazer do ressentido está ligado com a vingança. O mais importante, contudo, é lembrar que essa vontade de vingança não começa no professor. Ela o precede. Ela o faz querer. A vontade de vingança, a moral do ressentido capturou o coração, o desejo, o querer deste professor. O professor pune o aluno, pois acredita firmemente na razão, na verdade racional. Ou seja, todos os dispositivos disciplinares como a punição, as notas, as avaliações, as chamadas, necessitam de uma metafísica racional. Essa metafísica precede os dispositivos disciplinares. Mas precede também o corpo sem órgãos (Deleuze, 1996) do professor. Ou seja, os afectos e perceptos do professor são agenciados pela metafísica racional. Não se trata apenas de acreditar na verdade de uma forma consciente, mas de ser tomado por ela, de ser hipnotizado, seduzido, arrastado por ela.

Haveria, porém, um modo de libertar o docente dessa terrível prisão? Eis a grande pergunta colocada por Nietzsche na última fase de sua obra. Como curar esta doença horrível chamada ressentimento? A resposta encontrada pelo pensador alemão, é considerada por ele como o maior presente que já foi dado à humanidade. Presente de uma bondade sem limites. O grande zelo para com todas as gerações seguintes.

O professor, que sempre se considerou um dispéptico, pela primeira vez, em toda sua vida, questiona-se sobre o ressentimento. Seria esta sua doença? Estariam suas aulas enfermas? Caso sim, a cura prometida pela postagem de Gilberto parecia anunciar-lhe uma nova docência. Caso não, pensava ele, navegando pelo Facebook, não faria mal nenhum dar só uma espiadinha! O professor clicou, então, no hiperlink que havia abaixo do texto, abrindo um vídeo no youtube, em que o "próprio" Friedrich Nietzsche apareceu dizendo: 
E se um dia ou uma noite, um demônio se introduzisse na tua suprema solidão e te dissesse: "Esta existência, tal como a levas e a levaste até aqui, vai-te ser necessário recomeçá-la sem cessar, sem nada de novo, ao contrário, a menor dor, o menor prazer, o menor pensamento, o menor suspiro, tudo o que pertence à vida voltará ainda a repetir-se, tudo o que nela há de indizivelmente grande ou pequeno, tudo voltará a acontecer, e voltará a verificar-se na mesma ordem, seguindo a mesma impiedosa sucessão, esta aranha também voltará a aparecer, este lugar entre as árvores, e este instante, e eu também! A eterna ampulheta da vida será invertida sem descanso, e tu com ela, ínfima poeira das poeiras!" ... Não te lançarias por terra, rangendo os dentes e amaldiçoando esse demônio? Ou já vivestes um instante prodigioso, e então lhe responderias: "Tu és um deus; nunca ouvi palavras tão divinas!" Caso este pensamento te dominasse, talvez te transformasse e talvez te aniquilasse; perguntarias a propósito de tudo: "Queres isto outra vez e por repetidas vezes, até o infinito?" E pesaria sobre tuas ações com um peso decisivo e terrivel! Ou então, como seria necessário que amasse a ti mesmo e que amasse a vida para nunca mais desejar nada além dessa suprema confirmação! (NIETZSCHE, 2012, p.179).

\section{SOBRE O ETERNO RETORNO DO RESSENTIMENTO E/OU ALUNO: QUERES ISSO MAIS UMA VEZ?}

De boas! Sem essa de investir energia nessas exigências acadêmicas. Tô mais para outra vibe. Tá ligado? Até agora, tudo foi rolando e dando certo. Graças a Deus. Quer dizer... Tá lá o TCC. Um pouco parado. Já esteve congelado. Sério?! Agora não tenho mexido nele. Mas está sob controle. Eu tenho mesmo é até o final do ano pra fazer. Se o professor-orientador não atrapalhar, pode rolar. Se bem que na Biblioteca não tem os livros de que necessito e o clima lá em casa não está pra manter a concentração. Parece até perseguição. Sendo assim, não resta muito a fazer. No final, vou mesmo ser aprovado. Assim foi até aqui. De boas! Há um aplicativo que me avisa quantas horas ainda restam até o dia da entrega desse "boneco". Irado! O app também indica quantas páginas eu devo escrever por dia. Com isso, vou mantendo o controle da situação. Às vezes, me vejo em descontrole. Quase todo dia. Tenho a sensação de que isso funciona como um tamagotchi. Quando não o alimento, me faz acordar durante a noite e perder o sono. Mas, o que eu fizer agora, tá no lucro. Não sei. Eu sei que é assim. Eu acho que sei que sei. Jura que isso serve pra alguma coisa? Quer dizer: Isso não serve mesmo pra nada. Tenho certeza de que não. Minha cabeça voa pra todos os lados, bagunçando a dureza incrivel que carrego em meus ombros. E, não me entrego ao desafio como todo mundo. Não tem negócio com esse troço.

O aluno ressentido rejeita ou foge do compromisso com sua formação. Ele está ali, única e exclusivamente, buscando aprovação. Esperando seu julgamento. Ao outro designa o ato de ser avaliado. Quem deve avaliá-lo é o destino dele. Ele não tem responsabilidade nesse sentido. E por isso sua ação está em variados tempos e lugares, divergentes do que acontece no aqui e agora. Defende a necessidade de passar nessa disciplina para fazer a seguinte e quando chega a disciplina seguinte, garante que precisa passar nessa para fazer o estágio e quando chega o estágio, precisa passar no estágio para fazer outro estágio. Passa, passará, quem de trás, ficará...

Desse modo, o ressentido se produz como alguém que tem sua vida sequestrada, roubada, capturada pela promessa de dias melhores (de viver como alguém que ele não é). Vive crendo na 
promessa de encontrar bons momentos em um Paraíso. Esteja o Paraíso neste mundo ou em outro. Assim, acredita que acordará da viagem, de fato, de boas, fixando-se em suas certezas. Seu ponto de vista é tomado como verdade ou o verdadeiro significado do mundo. O indivíduo ressentido torna-se inflexível à aceitação de outros pontos de vista, em algumas situações chegando a desqualificá-las para defender a sua "verdade".

O poder do ressentimento é portanto dirigido sobre o outro, contra os outros. Mas o ressentimento é uma matéria explosiva: faz com que as forças ativas tornem-se reativas. É preciso, então, que o ressentimento se adapte a essas condições novas, que mude de direção. É em si mesmo, agora, que o homem reativo deve encontrar a causa de seu sofrimento. A má consciência lhe sugere que deve procurá-la "nele mesmo, num erro cometido no passado, que deve interpretá-lo como um castigo". E o sacerdote aparece uma segunda vez para presidir a essa mudança de direção; "É verdade, minha ovelha, alguém deve ser causa do que tu sofres: mas tu mesmo és causa de tudo isso, tu mesmo és causa de ti mesmo (DELEUZE, 1976, p. 61).

Ele torna-se reativo quando sua existência concentra-se apenas em seus interesses e não os atinge. É por aí que seu sofrimento é multiplicado, submetendo-se às promessas tanto capitalísticas ou de ordem transcendental. Culpar o outro, procurar alguém para culpar. Por fim, acaba mesmo culpando a si por sofrer. Eis o ressentido em ação. Nietzsche (1995) sugere em Ecce Homo: torna-te aquilo que tu és. E ele nos sugere esse tornar-se aquilo que somos esperando que façamos a pergunta: Mas como? Como? Como posso me tornar aquilo que sou?

Não me envolvo com nada daquilo. Não digo que sim, tampouco que não. Sou pura contrariedade: Mariazinha do contra - os amigos assim me chamam. Se pedirem A, eu faço B. Copiar aquela matéria é uma penitência todos os dias. Por causa dos mandos e desmandos, pouco tenho vontade de ir à escola. O verbo aprender nem consta no meu dicionário. Deixei isso para a próxima encarnação (risadas). Me divirto quando pinta uma cena pra deboche. Bizarro! Dias atrás, a professora falava dos sentidos e das sensações do corpo. Foi ali que Carlito detonou. Uma bomba gástrica tomou conta da aula. Puro odor em meio ao calor. Mas que potência tem o guri! Admirável! Quer mais do que isso? De fato, uma experiência de sensação de fedor. Em meio àquele tumulto, o moleque não cansou de repetir, olhando no fundo dos olhos da Jararaca: Sou do abrigo, meu bem! Sou do abrigo, sem pai e mãe também. Nunca esqueça disso. [É claro que nenhuma profe vai bater de frente com um moleque abandonado]. Nesse dia, a aula passou rápida. Nem olhei no celular. Dali pra frente, era só gritaria e muita zoeira da boa. Terminamos com o trabalho daquela Velha chata. De tanto rir e me sacudir, acabei esquecendo, por uns minutos, dos cortes com canivete que ontem à noite fiz nos meus braços... É muita dor. É de muito tempo que vem essa dor.

Diz o filósofo que o ressentimento é forte fonte de ameaça para uma vida potente. Com ele, é produzido um organismo decadente, isto é, doente, de modo que "o despeito, a susceptibilidade doentia, a impotência em vingar-se, a inveja, o ímpeto do ódio, são venenos terríveis [...]" (Nietzsche, 1995 p. 34). Nessa direção, instala-se um querer-dominar por vias da apropriação e da incorporação do 
dominado que é colocado em posição de subjugado na relação com aquele que o domina. Eis aí o movimento da vontade de poder (Nietzsche, 1982).

O ressentido opera por negação da vida. Nega uma existência plena de vitalidade, seja por mutilações, por oposição ou tantas outras formas cotidianas de expressão. Com isso, torna-se apenas um órgão de reação. No que mais aposta é na reparação. Ele quer a reparação vinda do outro para aliviar seu ódio contra tudo e todos que the chegam como rejeitadores de si ou dos seus pontos de vista. Para tal, investe na vingança daquele ou daquilo que lhe magoou. A mágoa serve de alimento. $E$ de tanto se alimentar dela, adquire uma gorda saúde dominante, conforme ensina Nietzsche. Parafraseando Deleuze: qual educação bastaria para libertar a vida em toda a parte onde esteja aprisionada pelo homem e no homem? (DELEUZE; PARNET, 1997).

\section{COMO ALGUÉM SE TORNA AQUILO QUE É?}

O famoso tema das Odes Píticas de Píndaro - converter-se naquilo que se é - pode ser encontrado em vários momentos da obra de Nietzsche: Shopenhauer como educador - onde aparece como pano de fundo -; Humano Demasiado humano - no aforismo 263 -; A Gaia Ciência - nos aforismos 270 e 335 -; Assim Falava Zaratustra - o convalescente; a oferenda do mel -; e, finalmente, Ecce Homo - onde se transforma em título/lema autobiográfico (LARROSA, 2005). Mas esta fórmula nietzschiana, para funcionar, necessita de uma pergunta: como? Ou seja, o enunciado proposto pelo filósofo só faz sentido àqueles que o interrogam, já que o imperativo é realizado esperando que cada um de nós, seus leitores, façamos a seguinte pergunta ao autor: mas como? Como poderia tornar-me aquilo que sou? Nesse momento, quando a pergunta é colocada pelo leitor, professor Nietzsche surge, sorrindo, para responder: agindo de tal forma que queiras o eterno retorno de tuas ações. "[...] nada querer diferente, seja para trás, seja para frente, seja em toda a eternidade. Não apenas suportar o necessário, menos ainda ocultá-lo - todo idealismo é mendacidade ante o necessário - mas amá-lo" (NIETZSCHE, 1995, p. 51).

A cura do professor/aluno ressentido estaria, então, em amar a educação? Não necessariamente. Trata-se, antes, talvez, de afirmar um querer. Querer eternamente o que se pensa, o que se realiza ou deixa de realizar. Viver de tal forma que se queira a eterna repetição desse querer. Não mais fugir, não mais desejar escapar para as pequenas compensações - férias, Facebook, aquela fofoquinha maldosa sobre alguém etc. -, mas querer o aqui e o agora, querer o passado, bem como sua eterna repetição no futuro. "Aquele cujo esforço é a alegria suprema, que se esforce! Aquele que gosta sobretudo de repouso que repouse! Aquele que gosta antes de tudo de submeter-se, obedecer e seguir, que obedeça! Mas que saiba bem para onde vai a sua preferência e que não recue diante de nenhum meio!" (DELEUZE, 1997, p. 77).

O que está exatamente em questão? Vejamos: a fórmula do eterno retorno força o ressentido a uma nova posição ética com o mundo, ao mesmo tempo em que afirma o nobre em suas ações. "O 
pensamento do eterno retorno elimina do querer tudo o que cai fora do eterno retorno, faz do querer uma criação, efetua a equação querer = criar" (DELEUZE, 1976, p. 33). Quem pode querer mais uma vez? Quem pode desejar eternamente repetir suas ações? Apenas aquele que experimenta uma vida digna, uma vida que vale a pena ser vivida. Pois dizer sim a pergunta 'Queres isso mais uma vez'? é dizer sim à vida de maneira integral. Contudo, que tipo de existência, que modo de vida, que corpo suportaria tais condições? Apenas o corpo nobre.

Colocando a questão de outra forma: seria possível querer eternamente o ressentimento? Algum professor/aluno seria capaz de espalhar, em todos os cantos de sua existência, um eterno ressentir, retornando sempre à ferida, a dor, à vingança imaginária, ao ódio repulsivo? Ou seja, o que aconteceria se um ressentido se colocasse diante da fórmula do eterno retorno?

\begin{abstract}
O eterno retorno produz o devir-ativo. Basta referir a vontade de nada ao eterno retorno para aperceber-se de que as forças reativas não retornam. Por mais longe que elas vão e por mais profundo que seja o devir-reativo das forças, as forças reativas não retornarão. $O$ homem pequeno, mesquinho, reativo não voltará. Pelo e no eterno retorno, a negação, como qualidade da vontade de potência, transmuta-se em afirmação, torna-se uma afirmação da própria negação, torna-se um poder de afirmar, um poder afirmativo. É isto que Nietzsche apresenta como a cura de Zaratustra e também como o segredo de Dionísio: "O niilismo vencido por si mesmo", graças ao eterno retorno. Ora, esta segunda seleção é muito diferente da primeira: não se trata mais de eliminar do querer, pelo simples pensamento do eterno retorno, o que cai fora desse pensamento; trata-se de fazer, pelo eterno retorno, entrar no ser o que nele não pode entrar sem mudar de natureza. Não se trata mais de um pensamento seletivo, mas sim do ser seletivo, pois o eterno retorno é o ser e o ser é seleção. (Seleção = hierarquia) (DELEUZE, 1976, p. 34)
\end{abstract}

Ao se colocar diante do eterno retorno, o professor/aluno ressentido é por ele transformado, lapidado, educado. Para compreender o que está em jogo, é preciso, mais uma vez, lembrar que em Nietzsche não há propriamente um sujeito, uma identidade, um eu no sentido cartesiano e/ou kantiano.

[...] um pensamento vem quando 'ele' quer, e não quando 'eu' quero; de modo que é um falseamento da realidade efetiva dizer: o sujeito 'eu' é a condição do predicado 'penso'. Isso pensa: mas que este 'isso' seja precisamente o velho e decantado 'eu' é, dito de maneira suave, apenas uma suposição, uma afirmação, e certamente não uma 'certeza imediata'. E mesmo com 'isso pensa' já se foi longe demais; já o 'isso' contém uma interpretação do processo, não é parte do processo mesmo (NIETZSCHE, 1992, p. 23).

Ou seja, por um lado, o ressentimento não começa, necessariamente, no professor e/ou no aluno. Ninguém nasce ressentido, nem se torna de tal forma assumindo para si esse querer como horizonte existencial. Por outro lado, avaliar o problema - ressentimento - como influência social, como característica identitária culturalmente construída é, da mesma forma, um profundo equívoco. O que está em questão, para Nietzsche, não passa por uma suposta interioridade/interiorização do/no professor/aluno, mas sim por forças ativas e reativas hierarquizadas neste campo que nos habituamos a nominar, desde Kant, como sujeito.

Não se trata, portanto, de buscar a cura para esta terrível doença chamada ressentimento investigando - como o fazem muitas psicologias - um suposto espaço interno, algo que estaria "dentro" do professor/aluno, tal qual uma patologia individual. Da mesma forma, não basta ter consciência do 
mal que nos habita para nos livrarmos dele. Reduzir o ressentimento ao sujeito, simplificá-lo como um condicionamento interno - o qual bastaria conhecer, racionalizar, descondicionar para se ver livre seria ignorar as forças que produzem o ressentimento, bem como o próprio sujeito. Aplicando ao contexto a conhecida tese apresentada por Michel Foucault em Vigiar e Punir- O sujeito é mero efeito do poder (FOUCAULT, 2007) -, podemos avançar problematizando o ressentimento desse professor/aluno como um fenômeno que o antecede: conjunto de forças que, uma vez vetorizadas, regem seu pensamento.

Este sujeito - professor/aluno - não é culpado, portanto, pelo ressentimento que o habita. Pois um determinado conjunto de forças o antecede, obrigando-o a ser tal como é. Ao mesmo tempo, é justamente ao responsabilizar-se por seu querer, ao dizer "sim, quero isso mais uma vez. Sim, foi assim que eu quis. Sim, assim irei querer eternamente", que a rota pode ser alterada. Ou seja, não se pode curar o ressentimento com a consciência, já que ambos são produzidos pelas mesmas forças. Abençoar o passado, querer o que se foi, querer o que se fez: eis o grande ensinamento de Zaratustra.

A mudança do comportamento moral do indivíduo não é uma mudança determinada pela vontade consciente, mas pela própria organização do Eterno Retorno. Sob o signo do Círculo vicioso (independente do querer humano) é a própria natureza da existência, logo, também dos atos individuais, que se modifica intrinsecamente. Nietzsche afirma numa nota tão reveladora quanto breve: "Como acabo com o fatalismo: 1. Pelo eterno retorno e pela pré-existência. 2. Pela liquidação do conceito de 'vontade' (KLOSSOWSKI, 2000, p. 89).

Para falar sobre esta mudança moral do indivíduo - cura do ressentimento -, convidamos, agora, para estar conosco, professor Zaratustra. Como este professor não é um, mas muitos, o apresentaremos em dois momentos. O primeiro Zaratustra - que vamos chamar de Profeta do SuperHomem - professa, como muitos de sua geração, uma espécie de projeto, que pode ser anunciado, ensinado como a boa nova às multidões. Tal qual João Batista - que anunciava a vinda do Salvador -, este Zaratustra põe-se a anunciar a vinda do super-homem. "O super-homem é o sentido da terra. Que vossa vontade diga: o super-homem seja o sentido da terra" (NIETZSCHE, 2011 p. 14).

Este primeiro Zaratustra aponta como horizonte, um determinado querer à multidão em praça pública: matar Deus. Ou seja, o que ensina-nos este primeiro Zaratustra? Ensina-nos a construir pontes para o super-homem. E como poderíamos desenvolver essa lição? Aceitando a morte de Deus e transvalorando todos os valores. Há, ainda, nos ensinamentos desse professor algo de esperança, de 'para todos', de progresso, de bom futuro, de meta a ser alcançada. Mas que meta seria essa? A inocência, a criança. Sim, o super-homem anunciado por Zaratustra como meta da civilização é um corpo diferente do corpo do camelo - 'tu deves' -, bem como do corpo do leão - 'eu quero'. Ambos dialéticos e, portanto, agenciados pela moral do ressentido. O corpo da criança é leve, não sente mais o peso da morte de Deus, pode alegrar-se com ela, sorrir e festejá-la dionisiacamente. Tendo, finalmente, condições de possibilitar a criação de novos valores. "[...] que pode fazer a criança, que nem o leão pôde fazer? Por que o leão, tem de se tornar criança? Inocência é a criança, e 
esquecimento; um novo começo, um jogo, uma roda a girar por si mesma, um primeiro movimento, um sagrado dizer-sim" (NIETZSCHE, 2011, p. 28).

O segundo Zaratustra - que vamos chamar de Mestre do Eterno Retorno - é um professorcriança. Não ensina mais a inocência como meta a ser alcançada, mas ao experimentar a inocência pode dizer sim a ela, afirmando eternamente sua repetição. Os ensinamentos deste segundo Zaratustra não possuem mais um horizonte a ser alcançado. O profeta do projeto para todos cede lugar ao professor do sim, mais uma vez. A docência deste segundo Zaratustra não passa mais pelo ensino em praça pública, nem pela pesquisa sobre o homem superior, pois ele percebeu que, de uma forma ou de outra, todos - grandes e pequenos - desejavam o mesmo: algo para acreditar.

O dictum de Píndaro é agora a mensagem de um mestre que não diz nada e que não se dirige a ninguém. Zaratustra não oferece uma fé nova, mas uma exigência nova; não uma verdade da qual bastaria apropriar-se, mas uma tensão. Não Ihe vale a generosidade enganosa e interessada daqueles que dizem dar algo - uma fé, uma verdade, um saber -, mas para oprimir com aquilo que dão, para fabricar discípulos ou crentes. Não faz mais do que enriquecer a cada um de si mesmo, desvelar o que cada um é e o que tem de melhor, elevar cada um à sua própria altura, procurar em suma que cada um chegue a ser o que é (LARROSA, 2005, p. 73).

Este segundo Zaratustra seria, portanto, aquele que nos ensina, que nos educa para o eterno retorno. Importante é perceber que esta pedagogia zaratustreica não passa pela interiorização, apropriação, conscientização de algo, mas sim por uma relação com a própria vida. Nesse sentido, parece-nos que a ação de 'tornar-se aquilo que se é' está envolvida em uma prática ao mesmo tempo ética e pedagógica. A pergunta que aprendemos a colocar com o mestre do eterno retorno: 'como podemos nos tornar aquilo que somos?', envolve um conjunto de ações que nos parecem atravessadas por uma educação de si, uma invenção de si, artistagem, escultura, composição de conhecimentos.

Trata-se de uma educação para além das pedagogias representativas, para muito além do trabalho focado na apropriação consciente, na interiorização do conhecimento. Por isso, superar o ressentimento é colocar-se à disposição de outra ética. Uma ética em que as velhas dicotomias - bem $\mathrm{x}$ mal; verdade $\mathrm{x}$ ficção; vítimas $\mathrm{x}$ algozes; dentro $\mathrm{x}$ fora etc. - perdem suas cores identitárias extremadas e passam a habitar um mesmo território cinza. Uma ética em que a culpa e o espírito de vingança não sobrevivem ao retorno de si mesmas. Em que a consciência e a vontade individual são tratadas como quimeras infantis. Em que os fatalismos clássicos - raça, gênero, classe - bem como os contemporâneos - gene, hormônio, neurotransmissor - são desativados pela pré-existência. Esta ética será eternamente ensinada por um Zaratustra em devir professor:

A ética do nosso século inaugura-se com a superação nietzschiana do ressentimento. Contra a impotência da vontade com respeito ao passado, contra o espírito de vingança por aquilo que irrevogavelmente foi e não pode mais ser querido, Zaratustra ensina os homens a quererem para trás, a desejarem que tudo se repita. (...) O eterno retorno é, antes de tudo, vitória sobre o ressentimento, possibilidade de querer o que foi, de transformar todo "assim foi" em um "assim quis que fosse" - Amor fati (AGAMBEN, 2008, p.104). 


\section{REFERÊNCIAS}

1. AGAMBEN, Giorgio. O que resta de Auschwitz: o arquivo e a testemunha. Tradução de Selvino Assmann. São Paulo: Boitempo, 2008.

2. COSTA, Luís Artur. O corpo das nuvens: ouso da ficção na Psicologia Social. Fractal, Rev. Psicol. [online]. 2014, vol.26, n.spe, pp.551-576. ISSN 1984-0292. http://dx.doi.org/10.1590/1984$0292 / 1317$.

3. DELEUZE, Gilles. Nietzsche e a Filosofia. Tradução de Edmundo Fernandes Dias e Ruth Joffily Dias). Rio de Janeiro: Editora Rio, 1976. Nietzsche. Tradução de Alberto Campos. Lisboa: Edições 70, 1997. A llha Deserta e Outros Textos. Org. David Lapoujad. (Trad. Luiz Benedito Orlandi). São Paulo: lluminuras, 2006.

6. DELEUZE, Gilles; GUATTARI, Félix. Mil Platôs: capitalismo e esquizofrenia v. 3. (Trad. de Aurélio Guerra Neto et al). Rio de Janeiro: Ed. 34, 1996.

7. DELEUZE, Gilles; PARNET, Claire. L' Abécédaire de Gilles Deleuze. Entrevista com Gilles Deleuze. Editoração: Brasil, Ministério de Educação, "TV Escola”, 2001. Paris: Editions Montparnasse, 1997. 1 videocassete, VHS, son., color.

8. DOSTOIÉVSKI, Fiodor. Memórias do Subsolo. Tradução de Boris Schnaiderman. São Paulo: Editora 34, 2000.

9. KLOSSOWSKI, Pierre. Nietzsche e o Círculo Vicioso. Tradução de Hortência S. Lencastre. Rio de Janeiro: Pazulin, 2000.

LARROSA, Jorge. Nietzsche \& a Educação. Tradução de Semíramis Gorini da Veiga. Belo Horizonte: Autêntica, 2005.

11. MACHADO, Roberto. Nietzsche e a Verdade. São Paulo: Graal, 2002.

12. NIETZSCHE, Friedrich. Além do Bem e do Mal: prelúdio a uma filosofia do futuro. (Trad. Paulo Cesar de Souza). São Paulo: Companhia das Letras, 1992. 
13. Ecce Homo: como alguém se torna o que é. Tradução de Paulo Cesar de Souza. São Paulo: Companhia das Letras, 1995.

14 Genealogia da Moral: uma polêmica. (Trad. Paulo Cesar de Souza). São Paulo: Companhia das Letras, 2009.

15 Assim Falou Zaratustra: um livro para todos e para ninguém. Tradução de Paulo Cesar de Souza. São Paulo: Companhia das Letras, 2011. A Gaia Ciência. (Trad. Paulo Cesar de Souza). São Paulo: Companhia das Letras, 2012.

\section{Édio Raniere da Silva:}

Doutor em Psicologia Social e Institucional pela Universidade Federal do Rio Grande do Sul. Coordenador Adjunto do Curso de Psicologia da Universidade Federal de Pelotas - UFPel. Membro da Associação Brasileira de Psicologia Social - ABRAPSO - e do GT Subjetividade, Conhecimento e Práticas Sociais da Associação Nacional de Pesquisa e Pós-Graduação em Psicologia - ANPEPP.

\section{Carla Gonçalves Rodrigues:}

Psicóloga, Licenciada em matemática. Doutora em Educação (UFRGS). Professora associada do Departamento de ensino da Faculdade de Educação da UFPel e docente permanente do PPGE.

\section{Como citar este documento:}

DA SILVA, Édio Raniere; RODRIGUES, Carla Gonçalves. EDUCAÇÃO E PRODUÇÃO DE SUBJETIVIDADE: O RESSENTIMENTO COMO MÁQUINA DE PRODUZIR CORPOS DO(C)ENTES. Reflexão e Ação, Santa Cruz do Sul, v. 26, n. 2, ago. 2018. ISSN 1982-9949. Disponível em: <https://online.unisc.br/seer/index.php/reflex/article/view/11664>. Acesso em: ___. doi: http://dx.doi.org/10.17058/rea.v26i2.11664. 